\title{
Research Progress on the Mechanism of GA and ABA during Seed Germination
}

Zuo Yue $\mathrm{Xu}$ Yonghua $\unrhd$

Jilin Agricultural University, College of Traditional Chinese Medicine, National Engineering Research Center of Ginseng Breeding and Application, Changchun, 130118, China

$\checkmark$ Corresponding author Email: xuyonghua777@yeah.net

Molecular Plant Breeding, 2020, Vol.11, No.20 doi: $\underline{10.5376 / \mathrm{mpb} .2020 .11 .0020}$

Received: 23 Aug., 2020

Accepted: 25 Aug., 2020

Published: 18 Sep., 2020

Copyright $\odot \mathbf{2 0 2 0}$ Zuo and Xu, This article was first published in Molecular Plant Breeding in Chinese, and here was authorized to translate and publish the paper in English under the terms of Creative Commons Attribution License, which permits unrestricted use, distribution, and reproduction in any medium, provided the original work is properly cited.

Preferred citation for this article:

Zuo Y., and Xu Y.H., 2020, Research progress on the mechanism of GA and ABA during seed germination, Molecular Plant Breeding, 11(20): 1-8 (doi: $\underline{10.5376 / \mathrm{mpb} .2020 .11 .0020)}$

\begin{abstract}
The dormancy and germination of seeds are determined by the balance between the embryo growth potential and the binding force imposed by the seed coat. The germination of different seeds is not synchronized, and the stimulus required to promote germination varies greatly. Before germination, the seeds need to undergo water absorption, reactivate metabolic activities and redifferentiate embryonic tissues to mobilize nutrients stored in seeds and initiate meristematic activities. The transition from dry seeds to seedlings is highly sensitive to different environmental conditions, especially light, temperature and water. This response to environmental signals is regulated by one or more hormones. Various plant hormones regulate seed germination through highly complex interactions. Among them, the role of GA (gibberellin) and ABA (Abscisic acid) in regulating seed germination is particularly critical. This article reviewed the mechanisms by which GA and ABA control seed dormancy at the molecular level, and discussed the way they interact with other hormones. Finally, the development direction of plant hormone research on seed germination is prospected.
\end{abstract}

Keywords GA; ABA; Seeds; Dormancy; Germination

Plant hormones are natural signal molecules that regulate plants physiology, development, and to adapt to environmental stimuli, and have a wide range of physical and chemical properties. With the development of modern biochemical technology, more and more plant hormones have been discovered and recognized, currently including (but not limited to) abscisic acid, AX (auxin), BR (brassinosteroid), CTK (cytokinin), GA, ethylene, JA (jasmonic acid), SA (salicylic acid), and strigolactone, which play a pivotal role in regulating the developmental processes and signaling networks of plants in response to a wide range of biological and abiotic stresses. Plant life begins with seed formation, which is the carrier of the next generation of plant life cycle. Seed germination is affected by many factors, such as external temperature and humidity conditions, internal hormone changes. Hormone research during seed germination will help to understand the growth and development process of plants, thus guiding plant breeding and cultivation methods.

\section{The Role of ABA in Seed Germination}

ABA plays an important role in maintaining seed dormancy and regulating seed germination. It controls seed germination by controlling the germination of the radicle and inhibiting the loosening and expansion of the cell wall (Gimeno-Gilles et al., 2009). NCED (9-cis-epoxycarotenoid dioxygenase) and ABA8'OH (ABA 8'-hydroxylase) are the key enzymes in ABA metabolism. NCED is mainly involved in the synthesis of ABA, and ABA8'OH is a key enzyme in ABA catabolism, which is encoded by CYP707A (Millar et al., 2006). Overexpression of NCED delayed the germination of seeds, Arabidopsis cyp707a2 mutant seeds increased the ABA level and delayed germination (Zheng et al., 2015). ABA can be synthesized both in dormant seeds and non-dormant seeds, however, ABA catabolism is stronger in non-dormant seeds, and dormant seeds are more conducive to ABA synthesis, that is, dormancy induces changes in ABA metabolism (Millar et al., 2006).

ABA signaling is mainly composed of ABA receptor proteins PYR (pyrabactin resistence)/PYL (PYR1-Like)/ RCAR (regulatory component of ABA receptor), PP2C (phosphatase 2C), SnRK2 (SNF1-related protein kinase 2), 
transcription factor $\mathrm{ABFs}$ (ABRE binding factors)/AREBs (ABA responsive element binding proteins) and ABA-responsive element ABRE (Figure 1) (Klingler et al., 2010). ABA can enhance the expression of many genes related to dormancy. For example, AtPrl is involved in improving the dormancy ability of seeds. Atper1-1 mutants were shown to inhibit seed dormancy and the deletion of CYP707A gene can reduce the dormancy inhibition of atper 1-1 seeds (Chen et al., 2019).

\section{The Role of GA in Seed Germination}

GAs is a class of diterpene carboxylic compounds widely found in higher plants. Among the more than 100 types of GAs that have been found, only few GAs have biological activity, which can promote the expansion and development of organs, and the most common ones are $\mathrm{GA}_{1}$ and $\mathrm{GA}_{1} . \mathrm{GA}_{3}$ and $\mathrm{GA}_{4}$, which are synthesized from GA12 through GA20ox and GA3ox catalytic reactions (Hedden and Thomas, 2012). Numerous studies on GA biosynthesis-deficient mutants have also proved that GA is essential for seed germination. DELLA protein is an inhibitor of GA response and a class of growth inhibitors. It exists in many plants and belongs to the Gras (GAI, RGA and SCARECROW) transcription factor family. Different DELLA proteins play different roles in seed germination. For example, AtEXPA2 is a kind of expansin gene specifically expressed in Arabidopsis seed germination. The mutant of this gene delayed germination. DELLA mutant showed that RGL1, RGL2, RGA and DELLA were involved in inhibiting the expression of AtEXP2, and RGL1 played a leading role in controlling the expression of AtEXP2 (Yan et al., 2014). GA utilizes the formation of the GID1 (GA-INSENSITIVE DWARF1)GA-DELLA complex to decompose the DELLA protein to alleviate the inhibition of GA response by DELLA and promote plant growth (Figure 2) (Nelson and Steber, 2016).

A.
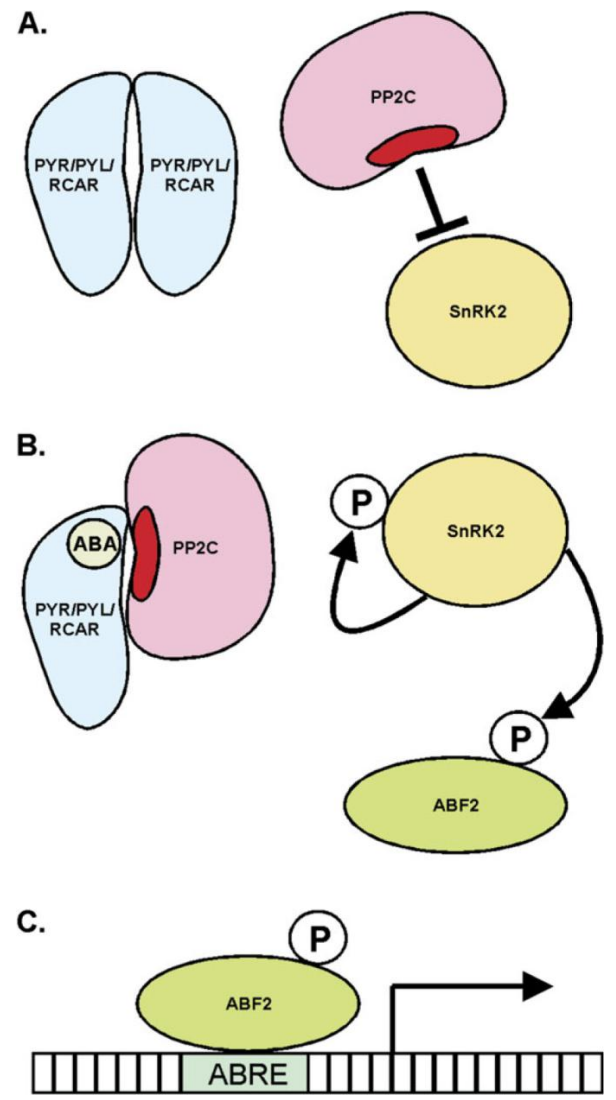

Figure 1 Schematic diagram of the ABA signal-receptor complex

Note: A: In the absence of ABA, the receptor forms a homodimer, while the PP2C inhibits both autophosphorylation of the SnRK2 and phosphorylation of ABF2; B: In the presence of ABA, a receptor protomer engulfs the hormone within a pocket, allowing the receptor to bind the PP2C and cover the phosphatase active site. This permits the autophosphorylation of the SnRK2 and phosphorylation of its ABF2 substrate; $\mathrm{C}$ : ABF2 binds to an ABRE in the promoter of ABA-responsive genes, activating transcription 


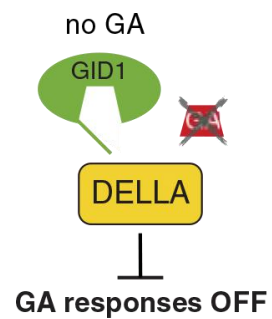

(a)

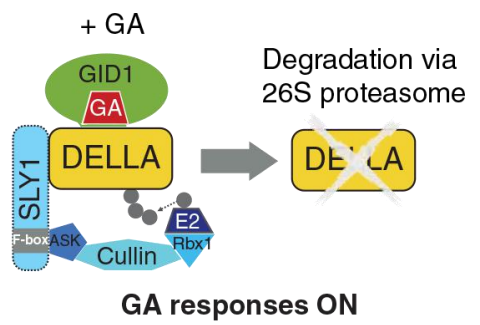

(b)

Figure 2 Schematic diagram of GA signaling

Note: (a) In the absence of GA, DELLA proteins are stable and repress GA responses; (b) GID1 binding to GA allows formation of the GID1-GA-DELLA complex, which in turn allows the SLY1/GID2 F-box protein to bind and polyubiquitinate DELLA, thereby targeting DELLA for destruction by the 26S proteasome; This lifts DELLA repression of GA responses

\section{Interaction of ABA/GA in Seed Germination}

\subsection{The interaction of $A B A$ and GA in metabolism}

A large number of genetic studies on ABA and GA biosynthesis and signal mutations have shown that these two hormones have important antagonistic effects in dormancy and germination. GA promotes the release of seed dormancy and counteracts the effect of ABA. The ratio of ABA and GA is the main regulator of plant seed dormancy. Under suitable growth conditions, the GA biosynthetic pathway is activated, prompting the release of the inhibitory effect of ABA. For example, in cotton seeds, the level of ABA decreased continuously from after-ripening, and when the content of ABA decreased to a lower level, GA began to play a role, which changed significantly during seed germination (Wang et al., 2019). The expression of GA3ox1 and GA3ox2 in ABA deficient mutant ba2-2 is higher than that in wild type, and GA biosynthesis of aba2-2 mutant is also activated during seed germination indicating that ABA is involved in the inhibition of GA biosynthesis (Seo et al., 2006; Toh et al., 2008). aba2-2 also showed a decrease in the expression of SPY (SPINDLY) during seed imbibition under high temperature, indicating that ABA can promote the expression of the negatively regulated gene $S P Y$ of GA signaling(Toh et al., 2008). ABA and GA also have tissue-specific and spatio-temporal differences in the regulation of seed dormancy and germination. GA20ox3, GA3ox1 and GA2ox5 in the endosperm of imbibing barley grains had relatively high expression, while GA3ox2 is highly expressed in embryos; the ABA biosynthesis genes NCED1 and NCED2 were transcribed in the endosperm tissue, while in the late stage of seed maturation, both the ABA catabolism gene CYP707A1 is transcribed (Park, 2015). NCED 9 has a negative effect on GA biosynthesis. The germination rate of $n c e d 9$ mutant treated with paclobutrazol and GA biosynthesis inhibitor is higher than that of wild type, indicating that ABA biosynthesis regulated the GA synthesis pathway of seeds (Seo et al., 2016). ABA and GA interact not only in metabolism, but also in many transcription factors and dormant genes.

\subsection{Interaction between ABA and GA in signal transduction}

DELLA can inhibit the growth of plants by promoting the accumulation of ABA. The ABA content of DELLA-Q mutant is significantly lower than that of wild type (Guo et al., 2014). Both RGL2 and RGL3 can inhibit seed coat rupture, and $\mathrm{ABA}$ can promote the transcription of $r g l 2$ and $r g l 3$, rgl3 is greatly affected by ABA, RGL2 plays a leading role in inhibiting the process of seed coat rupture (Piskurewicz and Lopez-Molina, 2009). ABI3 (ABA-INSENSITIVE3), ABI4 and ABI5 are transcription factors in ABA signal transduction, and the expression in dormant seeds is higher than seeds with lower dormant levels, which can inhibit GA biosynthesis (Shu et al., 2013; Zhao et al., 2018). RGL2 and ABI5 can work together to inhibit seed germination, RGL2 promotes ABA biosynthesis in the endosperm, and then ABA is released into the embryo to ensure the expression of ABI5, thereby inhibiting seed germination (Lee et al., 2010).

\subsection{The role of dormant genes in the interaction between $A B A$ and GA}

The expression of DOG1 (DELAY OF GERMINATION1) gene determines the depth of dormancy of seeds. The newly harvested seeds have higher expression of $D O G 1$, and as the after-ripening progresses, dormancy is gradually released and the transcription level of $D O G 1$ decreases (Nakabayashi et al., 2012). Low temperature can promote the 
expression of $D O G 1$ gene, $D O G 1$ promotes the expression of GA2ox6, a gibberellin catabolism gene, affects the $\mathrm{ABA} / \mathrm{GA}$ value in the seeds, and the absence of DELLAs and ABA will lead to the decrease of $\operatorname{dog} 1$ expression (Kendall et al., 2011). High temperature can induce SOM (SOMNUS) transcription, which encodes a CCCH type zinc finger protein. The protein can regulate the metabolism of ABA and GA at the same time, resulting in the accumulation of $\mathrm{ABA}$ and the decrease of GA, then the ABA/GA ratio increases and inhibits the germination of Arabidopsis seeds (Lim et al., 2013). MFT (MOTHER-OF-FT-AND-TFL1) is a strong promoter of seed dormancy. During seed germination of wheat (Triticum aestivum L.), low temperature or promoter mutation lead to up regulation of MFT expression and enhancement of seed dormancy (Chono et al., 2015). ABA regulates the expression of MFT through ABI3 and ABI5. The former acts as an inhibitory factor and the latter acts as a promoter. MFT directly inhibits ABI5 and negatively regulates ABA signaling pathway; on the other hand, GA down regulates MFT expression through DELLA protein and inhibits ABA synthesis (Xi et al., 2010).

\subsection{The role of transcription factors in the interaction between $\mathrm{ABA}$ and GA}

PIL5 (PHYTOCHROME-INTERACTING FACTOR3-LIKE5), also known as PIF1, is an important transcription factor regulating GA and ABA signaling. PIF1 inhibited the active GA biosynthesis genes GA3oxl and GA3ox2, and indirectly activated GA catabolism genes GA2ox2; Meanwhile, PIF1 had the opposite effect on ABA biosynthesis genes, including ABA biosynthesis genes ABA1, NCED6 and NCED9, and ABA catabolic genes CYP707A2; PIF1 also promoted the expression of genes encoding DELLA proteins GAI and RGA (Finkelstein et al., 2008). Seed germination of many plants is triggered by sunlight, red light can promote the degradation of transcription factor PIF1, and PIF1 can promote SOM expression (Vaistij et al., 2018). SPT (SPATULA) is a multifunctional transcription factor, which can control the response of germination to cold and light, inhibit the expression of GA3oxl and GA3ox2, and regulate the expression of five transcription factor coding genes: $A B I 4, A B I 5, R G A, R G L 3$ and $M F T$, in which $A B I 4, R G A$ and $M F T$ are inhibited, $A B I 5$ and $R G L 3$ are induced (Vaistij et al., 2013). SPT, SOM, PIF1, ABI5, DELLA and MFT can jointly regulate ABA and GA signal pathways to complete the response to seed germination under red light (Vaistij et al., 2018).

\section{The Role of Other Hormones in the Interaction between ABA and GA}

Many hormones interact with $\mathrm{ABA}$ and GA, and control the germination of seeds through these interactions. Exogenous auxin can enhance the inhibitory effect of ABA on seed germination, auxin response factor ARF10 enhances the sensitivity of ABA, MIR160 can down-regulate the expression of three transcription factors ARF10, ARF16 and ARF17 in auxin signal; ARF10 and ARF16 enhance the promoting effect of ABA on seed dormancy by maintaining the expression of $A B I 3$ (Liu et al., 2013). Br can antagonize the inhibition of ABA on seed germination and promote seed germination by regulating plant reproductive development; MFT played a role in the regulation of seed germination by $\mathrm{ABA}$ and $\mathrm{Br}(\mathrm{Xi}$ and $\mathrm{Yu}, 2010)$. BIN2 (BRASSINOSTEROID INSENSITIVE2) is a key inhibitor of BR signal. During seed germination and postgerminative growth, BIN2 can phosphorylate and stabilize ABI5 in the presence of ABA, while active BRs inhibit the regulation of ABI5 by BIN2 (Hu and Yu, 2014). Ethylene can regulate the weakening and rupture of the endosperm cap, thereby counteracting the role of ABA (Linkies et al., 2009). SNL1 (SIN3-LIKE1) and SNL2 are two members of the histone deacetylation complex in Arabidopsis thaliana, which promote seed dormancy by regulating ethylene and ABA content in seeds simultaneously; the double mutant snll snl2 seed dormancy decreased, while the expression of ethylene biosynthesis (ACO1, ACO4) gene and ABA catabolism gene (CYP707A1, CYP707A2) increased (Wang et al., 2013). CTK promotes seed germination, and ABA can inhibit this effect by reducing CTK biosynthesis. AAR (Arabidopsis response regulator) is an important component of CTK signaling. Among them, A-type ARR4, ARR5 and ARR6 can negatively regulate the expression of $A B I 5$, making CTK resist the inhibitory effect of ABA, while ABI4 can directly bind to the promoter, which negatively regulates the transcription of ARR6, ARR7 and ARR15 (Wang et al., 2011; Huang et al., 2016). In addition, some newly discovered hormones have also been found to regulate seed germination. Stipalactone can reduce $\mathrm{ABA} / \mathrm{GA}$ by regulating $\mathrm{ABA}$ biosynthetic enzymes, thereby alleviating the thermal inhibition of seed germination; KAR (Karrikin) can promote the germination of seeds by promoting the expression of GA biosynthetic genes GA3ox1 and GA3ox2 (Toh et al., 2012; Meng et al., 2017). 


\section{Summary Points and Future Issues}

Plant endogenous hormones play a multi-functional chemical regulation role in the process of seed germination. At the molecular level, their metabolic pathways and signaling pathways are regulated by various transcription factors. $\mathrm{ABA} / \mathrm{GA}$ is considered to be an important factor affecting seed dormancy. GA promotes seed germination and needs to destroy DELLA protein. However, ABA has a positive regulation effect on ABI transcription factors and DELLA protein. DELLA protein in turn inhibits GA biosynthesis. Make ABA and GA form a feedback loop. ABA/GA is controlled by the stage of seed development and the environment. In this process, a variety of transcription factors are involved in the regulation of seed dormancy and germination, which affects the germination process of seeds. In the early stage of seed germination, GA sensitivity is low, ABA sensitivity is high, this situation will change with the deepening of germination process.

In addition, in the process of seed germination, other hormones will also affect the germination ability of the seed in various ways. Most of the hormones promote the germination of the seed, but auxin can synergize with ABA to jointly inhibit seed germination. At present, there are still many deficiencies in the study of the effects of other plant hormones on seed germination. Although the study of mutants can discover the relationship between related genes and phenotypes, the specific mechanism at the molecular level is not yet clear. The study of the molecular mechanism of multiple hormone signal crossings is helpful to construct a new map of hormone signal integration in plant development and environmental adaptation.

Seed dormancy and germination is a complex physiological process. Different types of plants have different mechanisms for regulating seed dormancy. Current researches on seed dormancy and germination are mostly focused on model plants, but less on other kinds of plants. A better understanding of the mechanism of plant hormones related to seed dormancy and germination is helpful to obtain new varieties with appropriate seed dormancy level.

\section{Authors' contributions}

Zuo Yue was the main executor of this paper, completing the data collection and writing the first draft of the paper; Xu Yonghua was the designer and person in charge of the thesis, who guided the writing and revision of the thesis. The two authors read and approved the final manuscript.

\section{Acknowledgments}

This research was jointly funded by the National Key R\&D Program Project (2017YFC1702101) and the Key Science and Technology R\&D Project of Jilin Province (20180201006YY).

\section{Reference}

Chen H., Ruan J., Chu P., Fu W., Liang Z., Li Y., Tong J., Xiao L., Liu J., Li C., and Huang S., 2019, AtPER1 enhances primary seed dormancy and reduces seed germination by suppressing the ABA catabolism and GA biosynthesis in Arabidopsis seeds, The Plant Journal, 101(2): 310-323 https://doi.org/10.1111/tpj.14542

Chono M., Matsunaka H., Seki M., Fujita M., Kiribuchi-Otobe C., Oda S., Kojima H., and Nakamura S., 2015, Molecular and genealogical analysis of grain dormancy in Japanese wheat varieties, with specific focus on MOTHER OF FT AND TFL1 on chromosome 3A, Breeding science, 65: 103-109 https://doi.org/10.1270/jsbbs.65.103 PMid:25931984 PMCid:PMC4374559

Finkelstein R., Reeves W., Ariizumi T., and Steber C., 2008, Molecular Aspects of Seed Dormancy, Annual Review of Plant Biology, 59: 387-415 https://doi.org/10.1146/annurev.arplant.59.032607.092740 PMid:18257711

Gabriele S., Rizza A., Martone J., Circelli P., Costantino P., and Vittorioso P., 2009, The Dof protein DAG1 mediates PIL5 activity on seed germination by negatively regulating GA biosynthetic gene AtGA3ox1, The Plant Journal, 61(2): 312-323 https://doi.org/10.1111/j.1365-313X.2009.04055.x PMid: 19874540

Gimeno-Gilles C., Lelièvre E., Viau L., Malik-Ghulam M., Ricoult C., Niebel A., Leduc N., and Limami A.M., 2009, ABA-Mediated Inhibition of Germination Is Related to the Inhibition of Genes Encoding Cell-Wall Biosynthetic and Architecture: Modifying Enzymes and Structural Proteins in Medicago truncatula Embryo Axis, Molecular Plant, 2(1): 108-119 https://doi.org/10.1093/mp/ssn092 
Guo W., Cong Y., Hussain N., Wang Y., Liu Z., Jiang L., Liang Z., and Chen K., 2014, The Remodeling of Seedling Development in Response to Long-Term Magnesium Toxicity and Regulation by ABA-DELLA Signaling in Arabidopsis, Plant and Cell Physiology, 55(10): 1713-1726 https://doi.org/10.1093/pcp/pcu102 PMid:25074907

Hedden P., and Thomas S. G., 2012, Gibberellin biosynthesis and its regulation, Biochemical Journal, 444(1): 11-25 https://doi.org/10.1042/BJ20120245 PMid:22533671

Hu Y., and Yu D., 2014, BRASSINOSTEROID INSENSITIVE2 interacts with ABSCISIC ACID INSENSITIVE5 to mediate the antagonism of brassinosteroids to abscisic acid during seed germination in Arabidopsis, The Plant Cell, 26(11): 4394-4408 https://doi.org/10.1105/tpc.114.130849 PMid:25415975 PMCid:PMC4277219

Huang X., Zhang X., Gong Z., Yang S., and Shi Y., 2017, ABI4 represses the expression of type-A ARRs to inhibit seed germination in Arabidopsis, The Plant Journal, 89(2): 354-365 https://doi.org/10.1111/tpj.13389 PMid:27711992

Kendall S.L., Hellwege A., Marriot P., Whalley C., Graham I.A., and Penfield S., 2011, Induction of Dormancy in Arabidopsis Summer Annuals Requires Parallel Regulation of DOG1 and Hormone Metabolism by Low Temperature and CBF Transcription Factors, The Plant Cell, 23(7): 2568-2580 https://doi.org/10.1105/tpc. 111.087643 PMid:21803937 PMCid:PMC3226211

Klingler J.P., Batelli G., and Zhu J.K., 2010, ABA receptors: the START of a new paradigm in phytohormone signalling, Journal of Experimental Botany, 61(12): 3199-3210 https://doi.org/10.1093/jxb/erq151 PMid:20522527 PMCid:PMC3107536

Lee K.P., Piskurewicz U., Turečková V., Strnad M., and Lopez-Molina L., 2010, A seed coat bedding assay shows that RGL2-dependent release of abscisic acid by the endosperm controls embryo growth in Arabidopsis dormant seeds, Proceedings of the National Academy of Sciences, 107(44): 19108-19113 https://doi.org/10.1073/pnas.1012896107 PMid:20956298 PMCid:PMC2973907

Lim S., Park J., Lee N., Jeong J., Toh S., Watanabe A., Kim J., Kang H., Kim D.H., Kawakami N., and Choi G., 2013, ABA-INSENSITIVE3, ABA-INSENSITIVE5, and DELLAs Interact to Activate the Expression of SOMNUS and Other High-Temperature-Inducible Genes in Imbibed Seeds in Arabidopsis, The Plant Cell, 25(12): 4863-4878 https://doi.org/10.1105/tpc.113.118604 PMid:24326588 PMCid:PMC3903992

Linkies A., Müller K., Morris K., Turečková V., Wenk M., Cadman C.S.C., Corbineau F., Strnad M., Lynn J.R., Finch-Savage W. E., and Leubner-Metzger G., 2009, Ethylene Interacts with Abscisic Acid to Regulate Endosperm Rupture during Germination: A Comparative Approach Using Lepidium sativum and Arabidopsis thaliana, The Plant Cell, 21(12): 3803-3822

https://doi.org/10.1105/tpc.109.070201 PMid:20023197 PMCid:PMC2814513

Liu X., Zhang H., Zhao Y., Feng Z., Li Q., Yang H.Q., Luan S., Li J., and He Z.H., 2013, Auxin controls seed dormancy through stimulation of abscisic acid signaling by inducing ARF-mediated ABI3 activation in Arabidopsis, Proceedings of the National Academy of Sciences, 110(38): 15485-15490 https://doi.org/10.1073/pnas.1304651110 PMid:23986496 PMCid:PMC3780901

Meng Y., Shuai H., Luo X., Chen F., Zhou W., Yang W., and Shu K., 2017, Karrikins: Regulators Involved in Phytohormone Signaling Networks during Seed Germination and Seedling Development, Frontiers in Plant Science, 7 https://doi.org/10.3389/fpls.2016.02021 PMid:28174573 PMCid:PMC5258710

Millar A.A., Jacobsen J.V., Ross J.J., Helliwell C.A., Poole A.T., Scofield G., Reid J.B., and Gubler F., 2006, Seed dormancy and ABA metabolism in Arabidopsis and barley: The role of ABA 8'-hydroxylase, The Plant Journal, 45(6): 942-954 https://doi.org/10.1111/j.1365-313X.2006.02659.x PMid:16507085

Nakabayashi K., Bartsch M., Xiang Y., Miatton E. Pellengahr S., Yano R., Seo M., and Soppe W.J., 2012, The Time Required for Dormancy Release in Arabidopsis Is Determined by DELAY OF GERMINATION1 Protein Levels in Freshly Harvested Seeds, The Plant Cell, 24(7): 2826-2838 https://doi.org/10.1105/tpc.112.100214 PMid:22829147 PMCid:PMC3426117

Nelson S.K., and Steber C.M., 2016, Gibberellin hormone signal perception: down-regulating DELLA repressors of plant growth and development, Annual Plant Reviews, Volume 49, 153-188 https://doi.org/10.1002/9781119210436.ch6 
Park S., 2015, Tissue specific expression of ABA and GA metabolic genes during grain development and with respect to dormancy and germination in barley, Thesis for M.S., Department of Plant Science Faculty of Agricultural and Food Sciences University of Manitoba Winnipeg, Supervisor: Dr. Belay T. Ayele

Piskurewicz U., and Lopez-Molina L., 2009, The GA-signaling repressor RGL3 represses testa rupture in response to changes in GA and ABA levels, Plant Signaling \& Behavior, 4(1): 63-65

https://doi.org/10.4161/psb.4.1.7331 PMid:19704711 PMCid:PMC2634076

Seo M., Hanada A., Kuwahara A., Endo A., Okamoto M., Yamauchi Y., North H., Marion-Poll A., Sun T., Koshiba T., Kamiya Y., Yamaguchi S., and Nambara E., 2006, Regulation of hormone metabolism in Arabidopsis seeds: phytochrome regulation of abscisic acid metabolism and abscisic acid regulation of gibberellin metabolism, Plant Journal, 48(3): 354-366

https://doi.org/10.1111/j.1365-313X.2006.02881.x

PMid:17010113

Seo M., Kanno Y., Frey A., North H. M., and Marion-Poll A., 2016, Dissection of Arabidopsis NCED9 promoter regulatory regions reveals a role for ABA synthesized in embryos in the regulation of GA-dependent seed germination, Plant Science, 246: 91-97 https://doi.org/10.1016/j.plantsci.2016.02.013 PMid:26993239

Shu K., Zhang H., Wang S., Chen M., Wu Y., Tang S., Liu C., Feng Y., Cao X., and Xie Q., 2013, ABI4 Regulates Primary Seed Dormancy by Regulating the Biogenesis of Abscisic Acid and Gibberellins in Arabidopsis, Plos Genetics, 9(6): e1003577 https://doi.org/10.1371/journal.pgen.1003577 PMid:23818868 PMCid:PMC3688486

Toh S., Imamura A., Watanabe A., Nakabayashi K., Okamoto M., Jikumaru Y., Hanada A., Aso Y., Ishiyama K., Tamura N., Iuchi S., Kobayashi M., Yamaguchi S., Kamiya Y., Nambara E., and Kawakami N., 2008, High Temperature-Induced Abscisic Acid Biosynthesis and Its Role in the Inhibition of Gibberellin Action in Arabidopsis Seeds, PLANT PHYSIOLOGY, 146(3): 1368-1385 https://doi.org/10.1104/pp.107.113738 PMid:18162586 PMCid:PMC2259091

Toh S., Kamiya Y., Kawakami N., Nambara E., McCourt P., and Tsuchiya Y., 2011, Thermoinhibition Uncovers a Role for Strigolactones in Arabidopsis Seed Germination, Plant and Cell Physiology, 53(1): 107-117

https://doi.org/10.1093/pcp/pcr176 PMid:22173099

Vaistij F.E., Barros-Galvão T., Cole A.F., Gilday A.D., He Z., Li Y., Harvey D., Larson T.R., and Graham I.A., 2018, MOTHER-OF-FT-AND-TFL1 represses seed germination under far-red light by modulating phytohormone responses in Arabidopsis thaliana, Proceedings of the National Academy of Sciences, 115(33): 8442-8447 https://doi.org/10.1073/pnas.1806460115 PMid:30061395 PMCid:PMC6099910

Vaistij F.E., Gan Y., Penfield S., Gilday A.D., Dave A., He Z., Josse E.M., Choi G., Halliday K.J., and Graham I.A., 2013, Differential control of seed primary dormancy in Arabidopsis ecotypes by the transcription factor SPATULA, Proceedings of the National Academy of Sciences, 110(26): 10866-10871 https://doi.org/10.1073/pnas.1301647110 PMid:23754415 PMCid:PMC3696787

Wang L.R., Yang X.N., Gao Y.S., Zhang X.Y., Hu W., Zhou Z., and Meng Y.L., 2019, Investigating seed dormancy in cotton ( Gossypium hirsutum L.): understanding the physiological changes in embryo during after-ripening and germination, Plant Biology https://doi.org/10.1111/plb.13005 PMid:31077623

Wang Y., Li L., Ye T., Zhao S., Liu Z., Feng Y.Q., and Wu Y., 2011, Cytokinin antagonizes ABA suppression to seed germination of Arabidopsis by downregulating ABI5 expression, The Plant Journal, 68(2): 249-261

https://doi.org/10.1111/j.1365-313X.2011.04683.x PMid:21699589

Wang Z., Cao H., Sun Y., Li X., Chen F., Carles A., Li Y., Ding M., Zhang C., Deng X., Soppe W. J.J., and Liu Y.X., 2013, Arabidopsis Paired Amphipathic Helix Proteins SNL1 and SNL2 Redundantly Regulate Primary Seed Dormancy via Abscisic Acid-Ethylene Antagonism Mediated by Histone Deacetylation, The Plant Cell, 25(1): 149-166

https://doi.org/10.1105/tpc.112.108191 PMid:23371947 PMCid:PMC3584531

Xi W., and Yu H., 2010, MOTHER OF FT AND TFL1 regulates seed germination and fertility relevant to the brassinosteroid signaling pathway, Plant signaling \& behavior, 5(10): 1315-1317 https://doi.org/10.4161/psb.5.10.13161 PMid:20935478 PMCid:PMC3115377 
Molecular Plant Breeding 2020, Vol.11, No.20, 1-8

Xi W., Liu C., Hou X., and Yu H., 2010, MOTHER OF FT AND TFL1 Regulates Seed Germination through a Negative Feedback Loop Modulating ABA Signaling in Arabidopsis, Plant Cell, 22(6): 1733-1748 https://doi.org/10.1105/tpc.109.073072 PMid:20551347 PMCid:PMC2910974

Yan A., Wu M., Yan L., Hu R., Ali I., and Gan Y., 2014, AtEXP2 Is Involved in Seed Germination and Abiotic Stress Response in Arabidopsis, Plos One, 9(1): e85208

https://doi.org/10.1371/journal.pone.0085208

PMid:24404203 PMCid:PMC3880340

Zhao X., Dou L.R., Gong Z.Z., Wang X.F., and Mao T.L., 2018, BES1 hinders ABSCISIC ACID INSENSITIVE5 and promotes seed germination in Arabidopsis, New Phytologist

Zheng C., Halaly T., Acheampong A.K., Takebayashi Y., Jikumaru Y., Kamiya Y., and Or E., 2015, Abscisic acid (ABA) regulates grape bud dormancy, and dormancy release stimuli may act through modification of ABA metabolism, Journal of Experimental Botany, 66(5): 1527-1542 https://doi.org/10.1093/jxb/eru519

PMid:25560179 PMCid:PMC4339608 